\title{
Men's vs Women's Words on Facebook: The Differences on the Use of Adjectives and Degree of Informality
}

\author{
Viqi Ardaniah, Universitas Airlangga
}

\begin{abstract}
The present study concerns the differences between woman's language and man's language when women and men post or give their comments in such a social media like Facebook particularly in their adjectives. The study aims to identify the adjectives used by women and men in their Facebook and figure out the degree of informality in their comments or walls. The data were collected from the writer's Facebook. A week observation on the Facebook wall along with its comments posted by the first 10 men and women was conducted. The adjectives were analyzed from the Biber's perspective (1999) and the degree of informality was analyzed based on what has been proposed by Chang and Swales (1999). The findings show that man's and woman's language in social media have different patterns from the common differences between men's and women's language.
\end{abstract}

Keywords: adjective; degree of informality; men's language; women's language

\section{Introduction}

Recently the differences between men's language and women's language have not only relied on spoken form, but also on written form. Some research found that men are different from women in their writing. Male writers prefer to have a closer distance with their reading by using such pronouns as we, us, and determiners, quantifiers (Argamon, Koppel, Fine, \& Shimoni, 2003). In addition, male writers use intensifiers at the beginning of the sentence less often than female writers do. In other words, female writers like using adverbs (intensifier) initially (Mulac, Wiemann, Widenmann, \& Gibson, 1988). Ardaniah (2018) found that in the use of adverbial conjunction in essay writing, men tend to have more various enumeration type of adverbial conjunction than women, while in the use of contrast/concession and apposition the number of these adverbial conjunctions in the men's essay writing is slightly more than that in the women's essay writing. Women's language features are marked with the use of extravagant adjective words, expletives, euphemism, and polite expression (Pan, 2011).

If the differences between men's language and women's language can be in the written form like in academic essay, these differences may also be seen in non-academic written form such as in social media. One social media which has been the most popular social network since it was launched is Facebook (Chaffey, 2018). By the end of 2017, the number of Facebook users in Indonesia reached 130 million which is $7.1 \%$ of Asia Facebook users (Internet World Stats, 2018). This paper aims to identify the differences on the use of adjectives and degree of informality between men's language and women's language in Facebook.

\section{Types of adjectives}

Adjectives can be divided into two main categories based on their meaning, known as semantic categories; descriptors and classifiers (Biber, Conrad, \& Leech, 2002). Descriptor refers to adjectives which describe color, size/quantity, time, emotion, and other characteristics, while classifier refers to relational/classificational/restrictive, affiliative, and topical. Most adjectives classified into classifiers are non-gradable, meaning that they cannot be used in comparative or superlative forms or they cannot take modifiers of degree such as *very additional or *more additional.

Biber, Conrad, and Leech (2002) suggest that adjective also has some syntactic roles. The most common adjective is predicative either as subject predicative which complements a copular verb or as object predicative which follows the direct object. Other syntactic roles of adjectives fall into adjective as postposed modifiers, adjectives as noun phrase heads, adjectives as linking 
expressions, adjectives as free modifiers, and adjectives as exclamations. As the postposed modifiers, the adjectives usually follow indefinite pronouns as heads such as they are doing everything possible to protect the workers. The adjectives as noun phrase heads can be modified by adverbs like the very handsome in this class gets the highest score. The adjectives as free modifiers sometimes occur at the initial or final position of a sentence. The adjectives can serve as exclamations; some examples include Awesome! Excellent! etc.

\section{Degree of informality}

Informality or formality can obviously be seen in the linguistic features that show the differences between woman's language and man's language in the spoken form. Some linguistic features proposed by Lakoff (1973), Wardhaugh (2006) and Holmes (2008) may indicate the degree of formality of the speakers. The features include hypercorrect grammar, supper polite form, and standard form. These features are mostly found in the women when they are involved in conversations. Thus, men are called to have more informalities in their conversation since they use less correct grammar, less polite form, and less standard form (Trudgill, 1972; Lakoff, 1975; Holmes, 1993; Eckert, 1997).

Informality in the use of language in the written form has some features. Hyland and Jiang (2017) mention that there are at least 10 informal features. This can be seen in Table 1.

Table 1: Informal features

\begin{tabular}{|c|c|c|}
\hline No & Feature & Example \\
\hline 1 & First person pronoun to refer to the author(s) & $I$, we \\
\hline 2 & $\begin{array}{c}\text { Unattended anaphoric pronoun referring to } \\
\text { antecedent }\end{array}$ & "This/ that /it is her business" \\
\hline 3 & Split infinitives & $\begin{array}{c}\text { "he needs to immediately clarify } \\
\text { the news" }\end{array}$ \\
\hline 4 & Sentence initial conjunctive adverb & "And she admitted it" \\
\hline 5 & Sentence final preposition & "I wonder what he looks $a$ t" \\
\hline 6 & Listing expressions & And so on, etc., and so forth \\
\hline 7 & $\begin{array}{c}\text { Second person pronoun/determiner referring to } \\
\text { the reader }\end{array}$ & $\begin{array}{c}\text { "you are sitting on a bench which } \\
\text { assigns you } \text { role disabled" }\end{array}$ \\
\hline 8 & $\begin{array}{c}\text { Contractions } \\
\text { "export figures won't improve } \\
\text { until economy is stronger" }\end{array}$ \\
\hline 9 & Direct questions & "what actions need to be taken?" \\
\hline 10 & Exclamations & "that is not the answer!" \\
\hline
\end{tabular}

Being informal in a written form has some features. Chang and Swales (2014) mention that being informal means having personal involvement. Informality reflects the spoken language characteristics of fragmentation. Besides, there is a complex vagueness of ideas represented in the use of demonstrative pronouns like that or this in the written form (text).

\section{Discussion}

One week of observation on the writer's Facebook involving some comments on the wall and its comments was conducted. Some comments written either in English or Indonesian language from 15 female Facebook users and 15 male Facebook users were randomly chosen as the data. The comments could not exceed 50 words. At first, the words in the comments were identified based on the syntactic roles, so that the type of adjectives could be figured out. The most frequently appearing adjectives in the comments of female Facebook users were compared to those in the male Facebook users' comments. Then, the comments written by the female and male Facebook users would be identified based on the ten features of informality as seen in Table 1. 
In the use of adjectives, specifically in particular types, there are no big differences between the female Facebook users' comments and the male Facebook users' comments. In terms of semantic categories, adjectives that were not found in both comments are color and time. Evaluative/emotive adjectives, miscellaneous descriptive adjectives, relational adjectives, and topical adjective were found and their frequency of occurrences in both comments was the same. However, affiliative adjective could only be found in the male Facebook users' comment and topical adjective could be found in the female Facebook users' comment in which there were more emotive adjectives found than in the male Facebook users' comment. Compared to other types of adjectives, attributive adjectives were frequently used by the female and male Facebook users, but this adjective was more frequently used by the male Facebook users than the female Facebook users. Meanwhile in terms of syntactic roles, subjective predicative, adjective as postposed modifiers, adjective as noun phrase head, and adjective as exclamations were not found. Adjectives as free modifiers and as linking expressions are only found in the female Facebook users' comment. On contrary, adjectives as noun phrase head are only found in the male Facebook users' comment.

In terms of degree of informality, the female Facebook users have more features of informality in their comments than the male Facebook users do although some features are not found. From the words posted in the female and male Facebook users' comments, it has been found that split infinitive, sentence final preposition, and listing expression were not used by both, the female and male Facebook users. Contraction is the most frequent feature of informality found in both, but it is the female Facebook users who used it more often than the male Facebook users. The female Facebook users posted direct question and sentence initial conjunction in their comments. In contrast, none of the male Facebook users posted these two features of informality in their comments. The male Facebook users had unattended anaphoric pronoun, while the female Facebook users did not have the unattended anaphoric pronoun. Overall, the female Facebook users may have all the features of informality that the male Facebook users have, but the male Facebook users do not have particular features that the female Facebook users have.

Over some years, since Lakoff (1973) proposed some linguistic features that women have, women in a spoken language or a conversation have been described to have polite forms of speech. This may not be in line with the current findings in which the female Facebook users tend to have more features of informality. As Mizokami (2001) pointed out, the contexts and situations should be taken into account in determining the women's language that is different from the men's language. Gender itself cannot be considered as the main factor for the differences of language between women and men (Xiao \& Tao, 2007). Some factors should be included such as social status, age, structure and function of a communicative event (Mizokami, 2001).

For certain types of adjectives and informality features, in this study the fact that the female and male Facebook users' words are not different is similar to the finding of Mizokami's study in 2003. Mizokami (2003) found that Japanese men and women are similar in using polite expressions in their conversation. The culture i.e., Japan where they belong has already affected their language. This is applicable in Indonesia where the male and female Facebook users' comments have been affected by their culture which they adopt.

\section{Conclusion}

To identify the differences of the language between men and women, we cannot merely concern the gender. We have to look at the context, situation, social class (level), age and other sociolinguistic aspects. Traditionally, men's and women's language are different; practically, these may not remain the same due to some aspects that need to be taken into account. The linguistic features that women usually have may be commonly used by men, or vice versa. One question that will arise is whether the linguistic features of women still exist in the future or will the linguistic features between men and women be interchanged. 


\section{References}

Ardaniah, V. 2018. Laki-laki vs perempuan: Penggunaan keterangan penghubung dalam tulisan akademis. Mozaik Humaniora, 1.

Argamon, S., Koppel, M., Fine, J., \& Shimoni, A.R. 2003. Gender, genre, and writing style in formal written text. TEXT, 23, 321-346.

Biber, D., Conrad, S., \& Leech, G. 2002. Longman student grammar of spoken and written English. Harlow: Longman.

Chaffey, D. 2018. Global social media research summary 2018. Smart Insights.

Eckert, P. 1997. Gender and sociolinguistics variation. In Coates, J (ed.). Reading in Language and Gender. Blackwell: Oxford.

Holmes, J. 2008. An introduction to sociolinguistics (3rd ed). London: Longman.

Holmes, J. 1993.Women's talk: The question of sociolinguist universals. Australian Journal of Communication, 20(3), 125-149.

Hyland, K., \& Jiang, F. 2017. Is academic writing becoming more informal? English for Specific Purposes, 45, 40-51.

Internet World Stats. Available at https://www.internetworldstats.com/stats3.htm.

Lakoff, R. 1973. Language and women's place. Language in Society, 2(1), 45-80.

Mulac, A., Wiemenn, J.M., Widenmann, S.J., \& Gibson, T.W. 1988. Male/female language differences and effects in same-sex and mixed-sex dyads: The gender-linked language effect. Communication Monographs, 55(4), 315-335.

Mizokami, Y. 2001. Does 'women's language' really exist? A critical assessment of sex difference research in sociolinguistics. Multicultural Studies, 1, 141-59.

Mizokami, Y. 2003. Ambiguous boundary between women's and men's speech in the Japanese language in the use of polite expressions. Studia Linguistica, 16, 105-26.

Pan, Q. 2011. On the features of female language in English. Theory and Practice in Language Studies, 1(8), 1015-1018.

Trudgill, P. 1972. Sex covert prestige and linguistic change in the urban British English of Norwich. Language in Society, 1(2), 179-195.

Wardhaugh, R. 2006. An introduction to sociolinguistics (5th ed.). UK: Blackwell Publishing Ltd.

Xiao, R \& Tao, H. 2007. A corpus-based sociolinguistic study of amplifiers in British English. Sociolinguistic Studies-Equinox publishing, 1(2), 241-273. 